\title{
ISOLATION OF NORMAL DECANE FROM PETROLEUM BY DISTILLATION AND EQUILIBRIUM MELTING ${ }^{1,2}$
}

\author{
By Johannes $\mathrm{H}$. Bruun ${ }^{3}$ and Mildred M. Hicks-Bruun
}

\section{ABSTRACT}

A midcontinent petroleum was fractionated by distillation into cuts with boiling ranges of $0.5^{\circ} \mathrm{C}$ : From the cuts boiling in the neighborhood of $172^{\circ} \mathrm{C}$. $n$-decane was isolated by systematic equilibrium melting in a low-temperature centrifuge. By this method $n$-decane with a purity above 99.999 mole per cent was obtained. The following physical constants were determined for the pure hydrocarbon: Freezing point, $-29.68^{\circ} \mathrm{C}$.; boiling point, $+174.0^{\circ} \mathrm{C}$.; specific gravity $d_{4}^{20}, 0.72994$; refractive index $n \underset{\mathrm{D}}{25}, 1.4096$; and aniline point, $77.6^{\circ} \mathrm{C}$.

It was calculated that about 0.6 per cent of the crude petroleum consisted of $n$-decane.

\section{CONTENTS}

Page

I. Introduction

II. Methods employed

III. Experimental procedure and results

1. Distillation

2. Equilibrium melting

IV. Discussion of the results

V. Acknowledgment.

VI. Literature cited... 589

\section{INTRODUCTION}

The presence of $n$-decane in different crude petroleums has been established by Mabery and Dunn (1) ${ }^{4}$ and by others (2). However, the methods employed by previous investigators involved subjecting the distillates to vigorous treatments with strong chemical reagents. By such treatment it is possible to destroy completely the branch chain and cyclic hydrocarbons and leave the normal and quaternary paraffin hydrocarbons only partially attacked. Markownikoff (3) digested the fractions with strong nitric acid. Mabery and Hudson (4) used a mixture of nitric and sulphuric acids, while Aschan (5) found that chlorosulphonic acid would react less rapidly with normal and quaternary hydrocarbons than with other types of petroleum compoiunds. By means of chlorosulphonic acid Shepard, Henne, and Midgley (6) were able to isolate $n$-decane of high purity from petroleum.

1 Financial assistance has been received from the research fund of the American Petroleum Institute. This work is part of project No. 6, The Separation, Identification, and Determination of the Constituents of Petroleum.

${ }_{2}^{2}$ Presented before the division of petroleum chemistry at the meeting of the American Chemical Society, New Orleans, La., Mar. 29, 1932.

3 Research associate for the American Petroleum Institute at the Bureau of Standards.

1 Figures in parentesis here and elsewhere in the text indicate reference given in the bibliography at the end of this paper. 


\section{METHODS EMPLOYED}

Since the ultimate object of this research project is not only to isolate and determine the normal paraffin hydrocarbons, but also the other constituents of petroleum it is evident that the separation in every case should be conducted without the aid of destructive chemical reagents. In the present investigation, the isolation of the $n$-decane has, therefore, been accomplished by means of distillation and subsequent fractionation by equilibrium melting.

\section{EXPERIMENTAL PROCEDURE AND RESULTS}

\section{DISTILLATION}

The crude petroleum used for this investigation was obtained from No. 6 well of South Ponca City, Kay County, Okla.

The properties (7) of the material have been reported in previous papers, together with a description of the preliminary distillation (8)

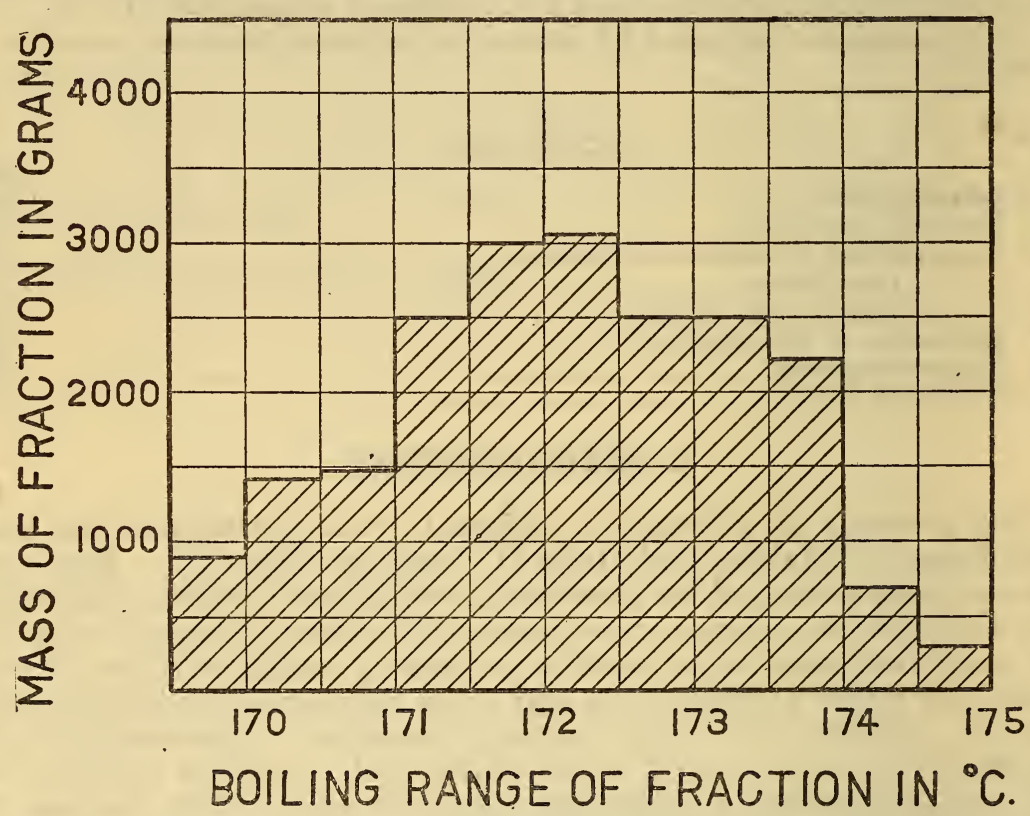

FIGURE 1.-Distribution of the fractions over their boiling ranges after the completion of the distillation

through a semicommercial column. Further distillations of the material were made by S. T. Schicktanz and a staff of assistants at this bureau by means of 30 -plate bubbling-cap stills of glass (9), (10). These distillations were made under a pressure of $215 \mathrm{~mm}$ and with a reflux ratio of about $8: 1$. The distillates were collected at a rate of about 1 to $2 \mathrm{ml}$ per minute. As a result of these distillations, a number of petroleum fractions were obtained, distributed according to boiling range in the manner shown in Figure 1. These boiling ranges have been corrected to $760 \mathrm{~mm}$ pressure. According to Figure 1 the largest volume of material is found between $171.5^{\circ}$ and 
$172.5^{\circ} \mathrm{C}$.; that is, about $2^{\circ}$ below the boiling point $\left(174^{\circ} \mathrm{C}\right.$.) of $n$-decane.

The refractive indices of the different cuts are shown by the graph of Figure 2. The minimum of this graph, exhibited by the two cuts boiling between $173^{\circ}$ and $174^{\circ} \mathrm{C}$., indicates that these fractions contain greater percentages of paraffin hydrocarbon than the others. The freezing points of the fractions were not accurately determined at this stage of the investigation. As should be expected, however, it was found that the fractions with boiling ranges between $173^{\circ}$ and $174^{\circ} \mathrm{C}$. could be solidified at considerably higher temperatures than the other fractions.

\section{EQUILIBRIUM MELTING}

During some of the preliminary experiments on the $173.0^{\circ}$ to $173.5^{\circ}$ C. fraction, it was discovered that the white crystalline material

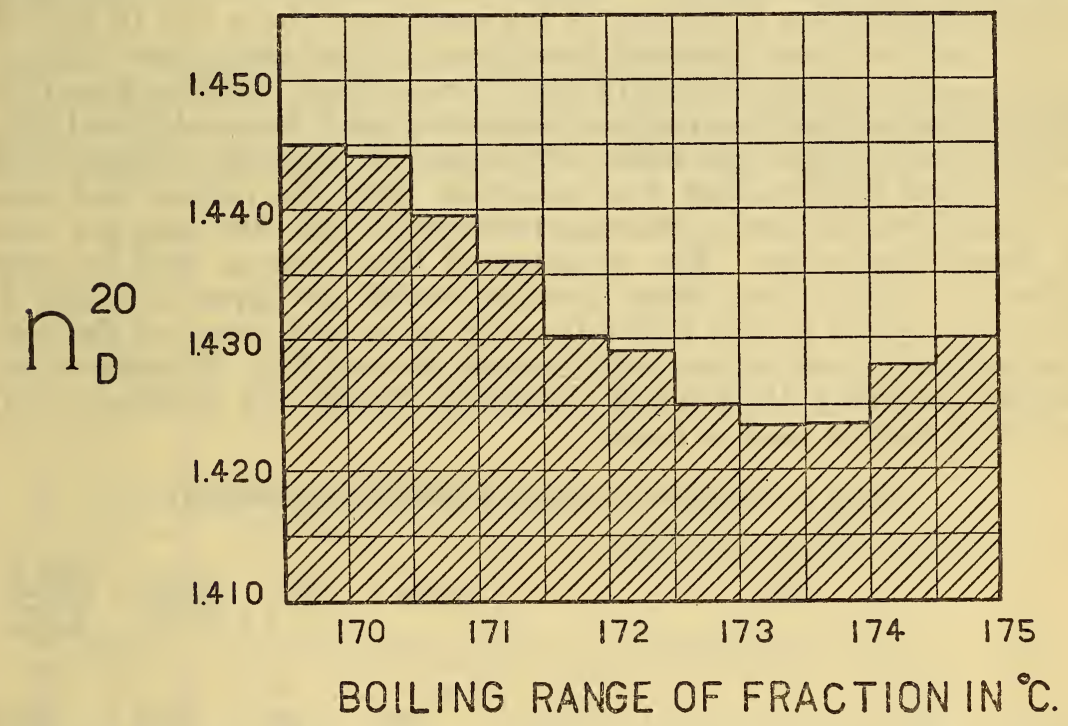

FIGURE 2.-The refractive indices plotted aginst the boiling ranges of the final distillates

which separated on cooling had physical constants which clearly indicated the presence of large quantities of $n$-decane. In order to isolate the $n$-decane from this as well as from the other cuts, a systematic fractionation by equilibrium melting was undertaken. The apparatus used for this work consisted of a freezing cylinder (with stirrer for impure and without stirrer for nearly pure decane) and a low-temperature centrifuge, and has been described in a previous paper (11). The technic employed was similar to that previously used for the purification of $n$-heptane and methylcyclohexane (11). The most satisfactory results were obtained when the temperature of the centrifuge was maintained about $2^{\circ}$ to $5^{\circ} \mathrm{C}$. above the initial freezing point of the material to be fractionated. In this way it was possible in a single fractionation to separate substantially pure $n$-decane from some of the cuts. 
In some cases the following method, suggested by R. T. Leslie, was used for fractionation of nearly pure $n$-decane: The material was precooled to about $-20^{\circ} \mathrm{C}$. and mixed with about one-third of its volume of methyl ether. Under constant agitation in a freezing cylinder this mixture was then cooled to a soft crystalline slush. By subsequent centrifuging practically all of the impurities. which were present in the $n$-decane, together with the methyl ether would separate in the "mother liquid." The removal of the last traces of impurities from the $n$-decane was further facilitated by washing the crystals on the rotating drum of the centrifuge with a small amount of methyl ether which previously had been cooled to about $-35^{\circ} \mathrm{C}$. Because of its low boiling point $\left(-24.9^{\circ} \mathrm{C}\right.$.), the methyl ether could easily be removed from the hydrocarbon fractions by gentle heating under reduced pressure.

Each of the cuts shown in Figure 1 was fractionated by one of the above-described methods of equilibrium melting. As a result of a single fractionation by means of the centrifuge about 500 to $800 \mathrm{ml}$ of the material was separated into three to five smaller cuts. Fractions having similar refractive index were mixed, yielding about 20 different lots covering a range of refractive index from 1.410 to 1.450 . Each of these lots was then refractionated and this procedure of mixing and fractionating was continued until the decane was concentrated into 11 lots containing between 91 and 100 mole per cent of this hydrocarbon. The amounts of these lots as well as their refractive indices and initial freezing points are given in Table 1. The last column in this table gives the calculated values of the concentration, in mole per cent of $n$-decane, for each lot. In these calculations the value 48.34 cal./g (Huffman, Parks, and Barmore (12)) was used for the heat of fusion.

TABLE 1.-Amounts of $n$-decane isolated from petroleum

\begin{tabular}{|c|c|c|c|c|}
\hline Lot & Volume & $n_{\mathrm{D}}^{25}$ & $\begin{array}{l}\text { Initial } \\
\text { freezing } \\
\text { point }\end{array}$ & $\begin{array}{l}\text { Purity in } \\
\text { mole per } \\
\text { cent } n- \\
\text { decsne }\end{array}$ \\
\hline 6 & $\begin{array}{r}m l \\
200 \\
150 \\
200 \\
800 \\
1,100 \\
1,600\end{array}$ & $\begin{array}{l}1.4096 \\
1.4098 \\
1.4100 \\
1.4102 \\
1.4104 \\
1.4108\end{array}$ & $\begin{array}{l}{ }^{\circ} C . \\
-29.68 \\
-29.70 \\
-29.78 \\
-29.80 \\
-29.98 \\
-30.20\end{array}$ & $\begin{array}{l}100.00 \\
99.88 \\
99.4 \\
99.3 \\
98.2 \\
97.0\end{array}$ \\
\hline $\begin{array}{l}7 \\
7 \\
9 \\
10 \\
11\end{array}$ & $\begin{array}{r}2,400 \\
400 \\
2,100 \\
900 \\
2,100\end{array}$ & $\begin{array}{l}1.4110 \\
1.4115 \\
1.4118 \\
1.4126 \\
1.4128\end{array}$ & $\begin{array}{l}-30.32 \\
-30.58 \\
-30.68 \\
-31.17 \\
-31.25\end{array}$ & $\begin{array}{l}96.2 \\
94.9 \\
94.3 \\
91.6 \\
91.1\end{array}$ \\
\hline
\end{tabular}

Referring to Figure 1, it should be noted that by far the greatest quantities of $n$-decane were isolated from the cuts boiling between $171.5^{\circ}$ and $174^{\circ} \mathrm{C}$. The concentration of $n$-decane in the cuts boiling: below $171.5^{\circ}$ and above $174.0^{\circ} \mathrm{C}$. diminished rapidly with the change in boiling temperature. 


\section{DISCUSSION OF THE RESULTS}

The identification of $n$-decane in the midcontinent petroleum was definitely established by comparing the physical properties of the purest sample of the isolated hydrocarbon (lot 1 in Table 1) with those of the purest samples of $n$-decane reported in the literature. The results of this comparison are shown in Table 2.

TABLE 2.-Physical constants of $n$-decane

\begin{tabular}{|c|c|c|c|c|c|}
\hline $\begin{array}{l}n \text {-decane } \\
\left(\mathrm{C}_{10} \mathrm{H}_{22}\right)\end{array}$ & $d_{4}^{20}$ & $n_{\mathrm{D}}^{25}$ & $\begin{array}{c}\text { Boiling } \\
\text { point } \\
\text { corrected }\end{array}$ & $\begin{array}{l}\text { Freezing } \\
\text { point } \\
\text { (in dry } \\
\text { air) }\end{array}$ & $\begin{array}{l}\text { Critical } \\
\text { solution } \\
\text { tempera- } \\
\text { ture in } \\
\text { aniline }\end{array}$ \\
\hline $\begin{array}{l}\text { Bruun and Hicks-Bruun } \\
\text { Shepard, Henne, and Midgley (6) } \\
\text { B. J. Mair (13). }\end{array}$ & $\begin{array}{r}0.72994 \\
.73014 \\
\end{array}$ & $\begin{array}{r}21.40960 \\
1.40986 \\
21.40961\end{array}$ & $\begin{array}{l}{ }^{\circ} C . \\
174.0 \\
174.06 \\
174.02\end{array}$ & $\begin{array}{c}{ }^{\circ} \mathrm{C} . \\
{ }^{3}-29.68 \\
-29.76 \\
34-29.68\end{array}$ & $\begin{array}{r}{ }^{\circ} C_{47.6} \\
77.5\end{array}$ \\
\hline
\end{tabular}

$1 \pm 0.00002$. Determined by the section of capacity and density of this bureau.

2 Determined by L. W. Tilton, of the optical division of this bureau.

a Determined by B. J. Mair by means of a platinum resistance thermometer calibrated by this bureau.

4 The freezing point of B. J. Mair's sample of synthetic $n$-decane was at first found to be $-29.76^{\circ} \mathrm{C}$. However, it was later submitted to fractionation by means of the centrifuge used in this work. Thus the freezing point was raised to the same final value $\left(-29.68^{\circ} \mathrm{C}\right.$.) as that of the $n$-decane isolated from petroleum.

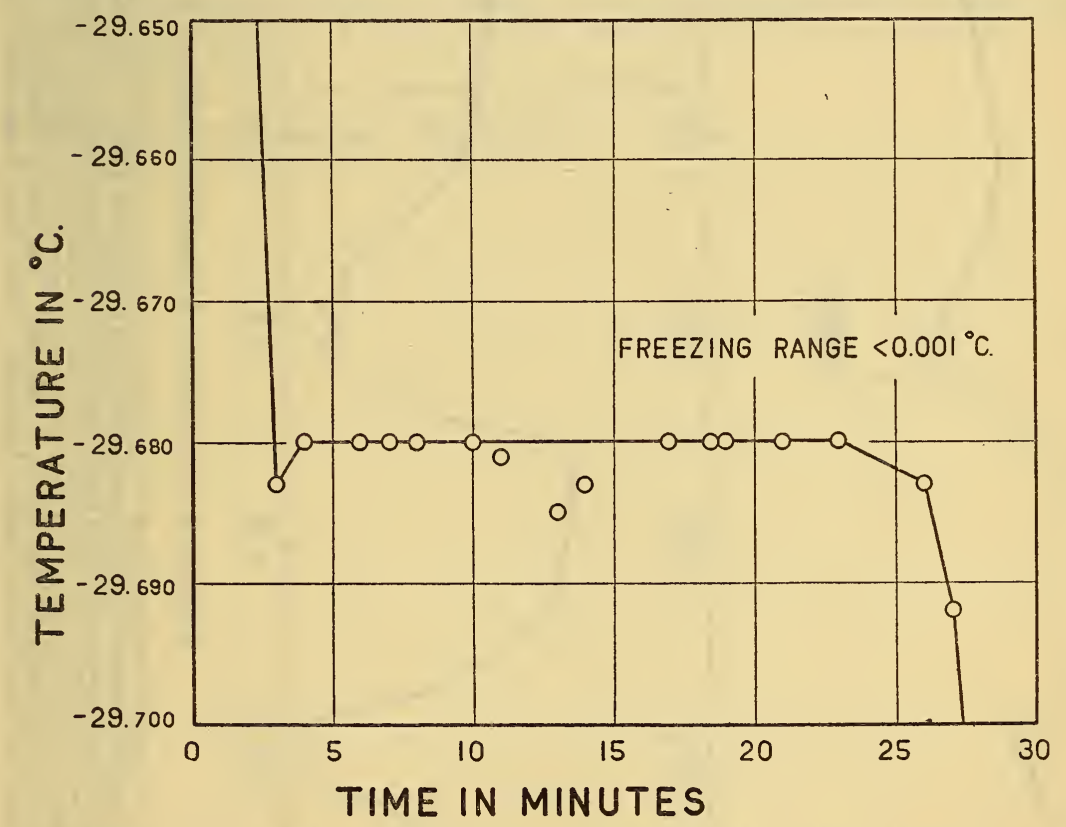

FIGURE 3.-The time-temperature freezing curve of the $n$-decane isolated from petroleum

The time-temperature cooling curve of the $n$-decane isolated from petroleum was obtained by B. J. Mair, of this bureau, using a platinum resistance thermometer and is shown in Figure 3. The whole sample froze solid within less than $0.001^{\circ} \mathrm{C}$. (neglecting the irregularities in the middle portion of the curve, due to insufficient stirring) and is consequently of an exceptionally high degree of purity (above 
99.999 mole per cent). The decane sample was subjected to further equilibrium melting by means of the centrifuge, but it was not possible to raise its freezing point above the determined value $-29.68^{\circ} \mathrm{C}$.

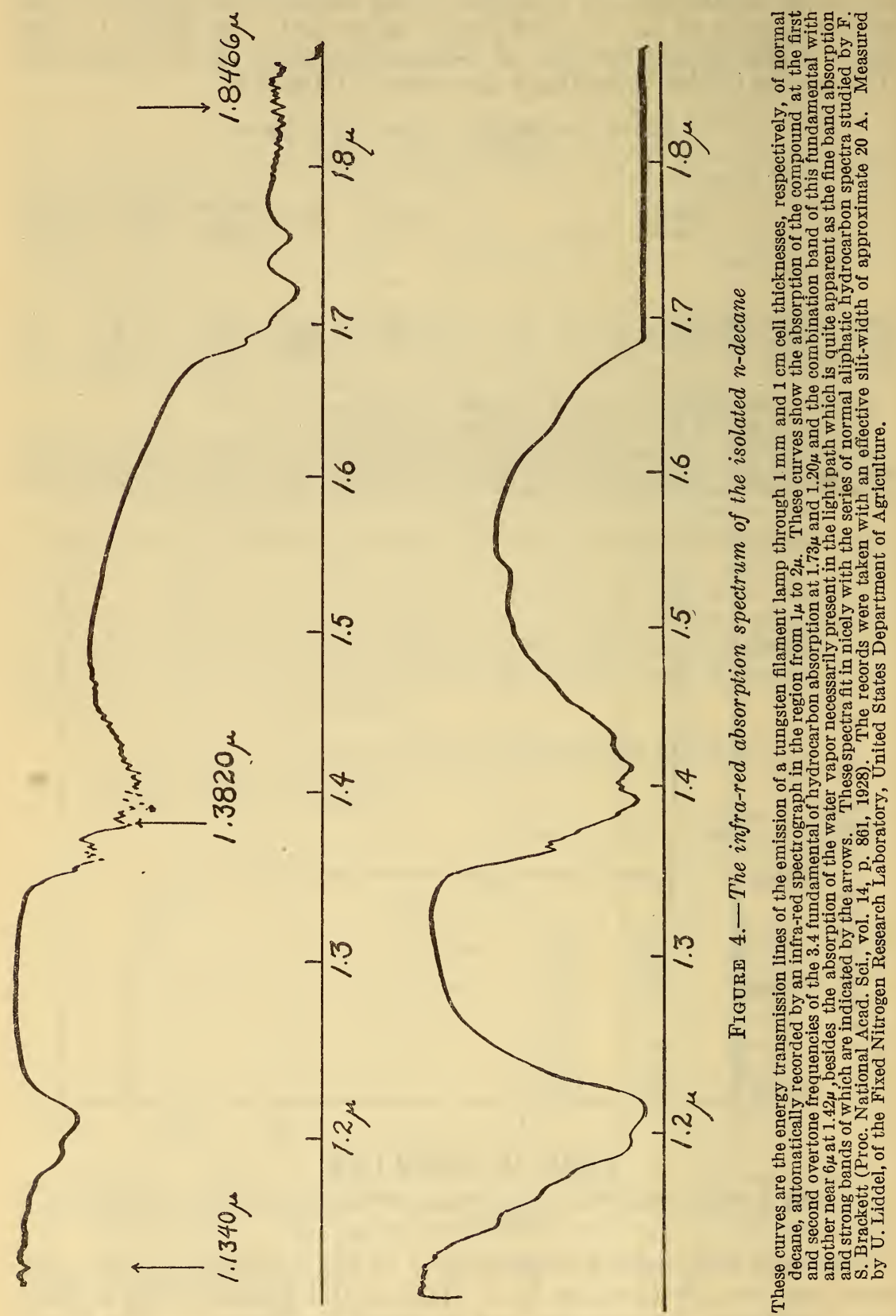

The infra-red absorption spectrum of the $n$-decane was measured by U. Liddel, of the fixed nitrogen research laboratory of the United States Department of Agriculture, and is shown in Figure 4. 
Based upon the total amount of the crude petroleum used (600 gallons of specific gravity 0.9) and including fractionation losses, it is estimated that the percentage of $n$-decane in the crude petroleum is about 0.6 .

\section{ACKNOWLEDGMENT}

The authors acknowledge the technical advice of E. W. Washburn, director of American Petroleum Institute project No. 6.

\section{LITERATURE CITED}

1. C. F. Mabery and O. C. Dunn, Am. Chem. J., vol. 18, p. 230, 1896.

2. Engler-Höfer, Das Erdöl, vol. 1, p. 246, Hirzel, Leipzig, 1913.

3. W. Markownikoff, Ber., vol. 32, p. 1445, 1899.

4. C. F. Mabery and E. J. Hudson, Am. Chem. J., vol. 19, pp. 482-485, 1897.

5. O. Aschan, Ber., vol. 31, p. 1801, 1898.

6. O. E. Shepard, A. L. Henne, and T. Midgley, jr., J. Am. Chem. Soc., vol. 53, p. 1948, 1931.

7. E. W. Washburn, J. H. Bruun, and M. M. Hicks, B. S. Jour. Research, vol. 3, p. 469, 1929.

8. J. H. Bruun and M. M. Hicks-Bruun, B. S. Jour. Research. vol. 7, p. 608, 1931.

9. J. H. Bruun, Ind. Eng. Chem., anal. ed., vol. 1, p. 212, 1929.

10. J. H. Bruun and S. T. Schicktanz, B. S. Jour. Research, vol. 7, pp. 851-882, 1931.

11. M. M. Hicks-Bruun and J. H. Bruun, B. S. Jour. Research, vol. 8, p. 432, 1932.

12. H. M. Huffman, G. S. Parks, and M. Barmore, J. Am. Chem. Soc., vol. 53, p. 3882,1931 .

13. B. J. Mair, B. S. Jour. Research, (unpublished).

WAshington, January 30, 1932. 